\title{
Study on Tax Evasion of Red-chip Listing
}

\author{
Wang Jing \\ Chongqing Vocational College of Commerce, 401331,China
}

\begin{abstract}
Key words: Red-chip listing; Tax evasion; Game; Offshore tax havens
Abstract: The red-chip listing is a phenomenon happened in the process of bypass listing of companies at abroad in our country's economic development. And it is a process that the domestic enterprises set up shell companies in the Cayman Islands, British Virgin Islands, and Bermuda and other offshore financial centers. The shell company purchases the assets of domestic enterprises, and then applies for listing in overseas in the name of the shell company outside to raise money at home. Although the red-chip listing, to a certain extent, solved the part of financing problems facing enterprises in our country, especially for small and medium-sized enterprises, at the same time, it has brought a lot of problems, such as the huge tax loss and loss of national wealth, etc.. How to effective deal with tax erosion problems caused by the red-chip listing also is a very realistic and important problem for us to take consideration.
\end{abstract}

\section{Introduction}

At present, the tax problem of our country's red-chip listing basically is in regulatory vacuum. Besides, there are no specific tax rules. The research of red-chip listing of our country and the problems of tax evasion can't be separated from the analysis of various specific questions and data related to the red-chip listing and tax evasion in practice. We need grasp the present situation, reason and channels, and analyze the red-chip listing and tax evasion in our country's practical situation, and analyze the influences the tax evasion of caused by red-chip listing could have on the various aspects of China's national economy, and finally get policy suggestions that are realistic and pertinent. As a result, the research of red-chip listing and tax evasion problems would be helpful to perfect our tax system. Besides, it is conducive to improve the system of China's foreign exchange and the supervision and management to the problem of Chinese enterprises' "foreign capital".

\section{The Definition of Tax Evasion Brought by Red-chip Listing}

To sum up, the tax evasion brought by red-chip listing refers to: the tax evasion phenomenon in our country tax revenue brought by the curve listed abroad act. And this act comes from the shell company's acquisition of domestic company assets and then list them at abroad directly.

For tax evasion brought by the red-chip listing, we need to pay attention to the followings:

(1) The red-chip listing is a kind of economic phenomenon happened in the process of China's reform and opening up and economic development. The red-chip listing, for the enterprises themselves, can solve part of financing problems of the enterprises' present situation. But for countries, this policy can cause tax loss and the loss of national wealth. Although due to the fact that the particularity of this kind of return of investment also can bring certain promoting effect to our country's economy, to this part of the large tax loss and loss of national wealth, this promoting effect is relatively small for the promotion of the economy. So while we studying on tax erosion problems brought by the red chip listing, we should stand analyze and regulate this phenomenon on the point of view of state and government. 
(2) In tax evasion the red-chip listing, there are a variety of tax evasion phenomena, in the above list of tax evasion. Such as tax evasion, tax fraud, tax revolt, tax delay, tax breaks and tax reduction, taxman violations, and tax reduction happened while the taxmen violating the tax rules in the levying process. The above phenomena are the main conditions leading to tax evasion.

\section{The Current Situation of Tax Evasion Brought by Red-chip Listing}

Because of the particularity of red chip listing model, there is space for the enterprise to evade and avoid tax, thus resulting in the loss of tax revenue.

Enterprises, through transferring into foreign companies, would result in the loss of income tax, customs duties and other taxes. China's current tax system conducts "double tracks" income tax policy towards domestic and foreign-capital enterprises, and taxes of domestic and foreign enterprises are not the same. And foreign-funded enterprises, to a certain extent, enjoy the preferential tax that is better national treatment. For productive foreign investment enterprises, for example, if they operated over 10 years, they could enjoy preferential treatment that two kinds of taxes are avoid and 3 kinds of taxes are halved. And again preferential investment tax refund, etc. And domestic enterprises enjoy the preferential treatment of income tax, which is achieved by red-chip listing, and buying domestic enterprises by their shell companies and transferring themselves into foreign enterprises.

Due to the fact that shell companies are set in the global optimal tax havens, and the main purpose is to transfer income and evade taxes. Although most of the assets and cash flow of shell companies are realized in domestic, and its income can be easily remitted abroad in the form of related party transactions and profits, and finally into the offshore financial centers to evade taxes. The quantity of the tax loss brought by red-chip listing is huge.

\section{The Thinking of the Management of Tax Evasion Brought by Red-chip Listing of Our Country}

Strengthen the Construction of Laws and Regulations of Red-chip Listing. The construction of laws and regulations of red-chip listing lies in regulating the behavior of the red-chip listing enterprises, rather than stopping or letting the red-chip listing go freely. So the law related to part needs to be continuously improved and perfected to meet the ever-changing situation in domestic and at abroad.

At present, the law that is proper to govern the red-chip listing in China is Regulation on Foreign Investors Merging and Acquiring Domestic Enterprises carried out on August 9, 2006 issued by the ministry of commerce, state-owned assets supervision and administration commission, the state administration of taxation, state administration for industry and commerce, the state administration of foreign exchange and the China securities regulatory commission jointly, and this regulation became effective on September 8, 2006. The main contents are the general rules, basic system, approval and registration, foreign investors with equity as a means of payment in mergers and acquisitions, antitrust review, six chapters of supplement. These regulations make China's specification about the red-chip listing plumper, especially the two chapters-the foreign investors with equity as a means of payment in mergers and acquisitions, antitrust review were no stipulated before. Therefore, the two chapters laid the following laws and regulations a good foundation.

But for some problems, such as taxes problems, the regulations are still in a regulatory vacuum state. The government should issue relevant regulations available for the red-chip companies, and the government could make them take actual management principle to run their companies in accordance with internationally accepted method for red chip listed companies, namely, no matter 
where the companies were registered, as long as the main business happened in China, their taxed should be levied in accordance with the Chinese tax law.

Improve the Tax System and Enhance the Supervision of Tax Regulation in China. In general, the government needs to improve the tax system and tax law in our country to avoid double paying of taxes, and realize the consistence between industry rate and the tax rate of the major foreign competitors. In this way, we can fundamentally weaken the motives of outsourcing enterprises. And the reform could be carried out mainly from the following several aspects:

1. Unify Income Tax of Domestic and Foreign Investment

(1) Unify enterprises' income tax rates.

(2) Unify the tax bases of enterprises' income tax.

(3) Unify the tax treatment methods of enterprise income tax assets.

(4) The preferential tax policy governance.

2. Build Enterprise Booking Tax Appraisal Mechanism

The so-called booking tax identification, namely, before or in the investment management behavior, to lock risks and avoid tax disputes, the enterprises apply to tax authorities for tax identification in advance. There are basically two kinds of tax identification methods, and one is tax consulting with a feasibility study of the tax's nature. If the tax treatment understanding is not the same as that of enterprise making enterprise's expected profit cannot reach the target level, then the appointment of tax treatment is likely to affect another investment or business decision. The other is pure tax identification, when the enterprise has already made an investment or business decision, but could not clearly define the taxes brought by this action, so the enterprise apply for the tax department for examination and approval before tax liability happens. In this way to make sure whether this behavior or income are taxable behavior in advance, and which tax is applicable and which tax rate should be chosen and so on.

3. Strengthen International Anti-tax Avoidance

(1) Perfect laws and regulations related the transfer pricing in China

In order to perfect the adjustment methods of transfer pricing, the government can take the following measures:

Introduce comparability analysis, and draw lessons from the OECD rules of comparability. For factors affecting the comparability and comparability in the application of transfer pricing, the government should adjust the methods, and make specific instructions.

Further refine various adjustment methods, and give detailed instructions on various adjustment methods, applicable conditions, applicable scope and the advantages and disadvantages. Besides, the government should list calculation formula of some legal cases.

(3) Expand the anti-tax evasion adjustment method, and add trading profits method recognized in the international management. Namely, take the comparable profits method and transaction net margin method as supplement methods to current methods, and at the same time, introduce the concept of normal trading range for the enterprises to adapt to the complicated international economic environment.

(2) Make the anti-tax evasion laws and regulations

Due to the need of encouraging foreign investment, China hasn't yet formulated specific anti-avoidance policy measures. But the government can try to launch regulations against tax havens at the appropriate time and at the same time draw lessons from the developed countries against tax havens and regulations. First, the government should make sure where the tax havens are, and draw lessons from western countries' definitions of tax havens and low-tax areas. And the government should limit the tax rates. Besides, the government should stipulate that all the 
country's corporate income tax rates that are lower than the certain percentage of the country or region, thus this region should be listed as tax havens or low tax area. Second, the government could flexibly limit its residents' immigration tax havens and using those havens to avoid taxes. Finally, the government can guide the taxes of tax-controlled foreign companies. For the taxpayers that are proper to use tax havens system, they must declare the company's financial position and undistributed profit to the tax authorities. And in which, the part belongs to the enterprise's share should be calculated out and be included in taxable income tax based on the shareholding in accordance with the law. But for the tax that has already surrendered at abroad in tax havens, the government should allow the enterprise deduct this part from the tax amount that should be surrendered in our country.

(3) Strengthen international cooperation

Strengthen international anti-tax avoidance in unilateral efforts alone is not enough. Besides, the government should also strengthen bilateral or multilateral international anti-avoidance tax coordination and cooperation. In international cooperation aspect of anti-tax avoidance, both the bilateral or multilateral approaches mainly embodied in the tax treaties regulating corresponding specifications of tax evasion, especially the anti-avoidance clauses, terms and terms related to tax information exchange and mutual negotiation. Beside, around the world, as the transnational collaboration among the same period auditing, tax collection and administration are also is being developed.

\section{Conclusion}

The current domestic researches on the problem of the red-chip listing all stay on the procedures and methods level, and few people research the red-chip listing from the theoretical level, the effects it has on the economy, and what the government should do to deal with the tax loss impact brought by red-chip listing on the economy. Therefore, in this paper, the author tries to theoretically analyze the red-chip listing economic phenomenon, and theoretically analyzed the tax evasion brought by red-chip listing. From the perspective of economics, the author analyzes the impact of red-chip listing on the economy and the rest of the enterprise. Beside, the author analyzes the positive and negative economic impacts brought by tax evasion in red-chip listing. Through the analysis of laws and regulations related to red-chip listing carried out by the government in different periods, the author analyzes the behavior of governments and enterprises. By establishing complete information static game model, the author obtains the mixed strategy Nash equilibrium of government and puts forward the real solution in realistic. By taking advantage of the experience of other countries about the international tax avoidance, the author puts forward the tax evasion problems brought by the red-chip listing and relevant suggestions. First of all the government should strengthen the construction of the laws and regulations of the red-chip listing. Secondly, the government should improve and enhance the tax system of our country' tax revenue regulations. Finally, the government should strengthen the supervision of international capital flow. Only from several aspects to deal with the tax evasion problem and strengthen the cooperation among government departments, can our government fundamentally solve the problem of the red-chip listing and the tax revenue loss.

\section{Reference:}

[1] Cross, R. and Shaw, G. k. . On the Economics of Tax Aversion . Public Finance, Vol.37. 
[2] Allingham, M.G. and Sandmo, A. Income Tax Evasion: A Theoretical Analysis. Journal of Public Economics, Vol.1,1972.

[3] Koo \& Partner. Legal Risk on Offshore Business. 2002.

[4] Dooley,M.P.1996,A Survey of Literature on Controls over International Capital Transactions, International Monetary Fund Staff Papers;Vol.43 Issue4,p639-688.

[5] Mossack \& Fonseca. Offshore Commercial Operation. 2002.

[6] Hampton, Mark, Macmillan. The offshore interface: tax havens in the global. 